\title{
Quality of Life Comparison in STEMI Patients with Percutaneous Coronary Intervention (PCI) and Non- PCI in Dustira Hospital
}

\author{
Prihati Pujowaskito*, Dinda Dwi Lazuardi Emha, Ilma Fiddiyanti, Rizki Bunawan \\ Faculty of Medicine \\ Jenderal Achmad Yani University \\ Cimahi, Indonesia \\ *prihati.pujo@fk.unjani.ac.id
}

\begin{abstract}
ST Segment Elevation Myocardial Infarction (STEMI) is one of the types Acute Coronary Syndrome (ACS) that often causes sudden death and one of the medical emergency cases that requires immediate reperfusion treatment. Reperfusion treatment are Percutaneous Coronary Intervention (PCI) or non-PCI (pharmacological therapy). According to the previous studies, both of the treatments differed in quality of life after the treatment. Changes in quality of life can be measured by the Seattle Angina Questionnaire (SAQ) which has five clinical dimensions, those are physical activity, frequency of pain, pain stability, patient satisfaction, and perception of the disease. The purpose of this study is to determine the difference in quality of life of STEMI patients with PCI action compared to non- PCI at Dustira Hospital Cimahi. This study used a comparative analytical method with a cross sectional study approach. Data was obtained from primary data with a questionnaire that was filled by 17 STEMI patients who were treated with PCI and 17 STEMI patients Iwith non-PCI in Dustira Hospital Cimahi. The data were analyzed statistically by an independent $T$ test. The result showed that the average quality of life scores of STEMI patients who were treated by PCI in Dustira Hospital Cimahi (66.06) was 13.88 points higher than STEMI patients who were treated with non-PCI (52.18). The quality of life of the PCI group in Dustira Hospital Cimahi is better than the non-PCI group because the mechanism of breakdown of atherosclerotic plaque by PCI-treated can immediately improve coronary blood flow so that tissue reperfusion can be restored. Statistically there is a very significant difference with $P$-value lower than 0.01 $(\mathbf{p}=\mathbf{0 , 0 0 0 0})$.
\end{abstract}

Keywords-STEMI, PCI, non-PCI, Quality of life, SAQ

\section{INTRODUCTION}

\section{A. Background}

Cardiovascular disease is a group of diseases that involve the heart and blood vessels and has been the leading cause of death and paralysis in the world [1]. According to the World Health Organization (WHO) estimated number of deaths due to cardiovascular disease in 2015 approximately 17.7 million people representing $31 \%$ of deaths worldwide. The biggest cause of the death rate is mainly caused by coronary heart disease (CHD), around 7.4 million deaths [2]. Estimated by 2020, the CHD will survive as a major threat to human life and death as well as is expected to be continues to increase to 23.3 million deaths in 2030 [3].

Coronary heart disease (CHD) is a disruption of heart function due to muscle heart blood deficiency caused by the narrowing of the coronary arteries [4-6]. This narrowing of the coronary vessels can be caused by a process called atherosclerosis or thrombosis. This results in decreased oxygen supply to the heart muscle (myocardial ischemia) and can cause reduced function heart muscle and the destruction of heart muscle cells, which is called acute myocardial infarction (IMA) or "heart attack" [7,8]. According to WHO in 2008, there were 7.3 million cases of death caused by IMA [1]

Acute coronary syndrome (ACS) is classified into three types of disease based on evidence of cardiac muscle damage inferred from the patient's symptoms, changes in the ST wave image on the electrocardiogram (EKG), and biomarkers heart indicating heart muscle death: ST segment elevation myocardial infarction (STEMI), non-ST segment elevation myocardial infarction (NSTEMI), and unstable angina (UA) [912]. Unstable angina (UA) and non-ST segment elevation myocardial infarction (NSTEMI) is usually characterized by a narrowing coronary arteries partially or intermittently, whereas STEMI occurs due to coronary arteries completely blocked [13].

ST segment elevation myocardial infarction (STEMI) is the cause of the main deaths from sudden cardiac arrest outside the Hospital, however in Hospital STEMI mortality has decreased $[14,15]$. ST segment elevation myocardial infarction (STEMI) is expected to continue to be a major health problem in industrialized countries as well as being an increasingly significant problem in developing countries, including Indonesia [16]. STEMI case is a medical emergency that requires immediate action [17]. Possible medical management 
options include reperfusion by revascularization of the arteries and administration of pharmacological therapy [18].

The action of revascularization of the arteries by means of Percutaneous Coronary Intervention (PCI) is a non-surgical intervention procedure using a catheter to dilate or open narrowed coronary vessels with a balloon or a stent [8]. Successful PCI action opens blocked coronary arteries in over $90 \%$ and continues to increase from year to year, compared to therapy pharmacological (non-PCI) [19]. PCI measures also provide quality improvements greater patient life to angina symptoms and exercise tolerance, and also reduce the need for drugs when compared to pharmacological therapy (non-PCI) [18].

According to the World Health Organization, quality of life is an individual's perception on the position of his life in the context of culture and the assessment system in environment in which they live and related to goals, expectations, and standard. Quality of life is a broad concept that can be influenced relatively by a person's physical health, psychological state, personal beliefs, and social relationships [20]. Quality of life in STEMI patients can be measured using the Seattle Angina Questionnaire (SAQ) instrument. The questionnaire consists of several clinical dimensions, namely physical activity, pain frequency, stability pain, patient satisfaction and patient perception of disease [21].

Seattle Angina Questionnaire (SAQ) uses a scoring system with range $0-100$ and the higher the score obtained indicates more good health status of the patient [22]. The score increase occurred in the patient group performed PCI measures compared to non-PCI. Among patients with angina is stable, those with PCI and non-PCI alone have experienced increase in health status while still getting further treatment. The PCI group has an additional, but more significant, benefit [23].

Based on the results of research by Weintraub [23], during the period advanced treatment in patients with stable angina, the percentage of patients who are free of angina significantly higher in the PCI group than in the medication therapy group for 24 months, which is about $53 \%$, but not significantly different between the two groups at 36 months. Larger proportion of the PCI group had a clinically significant improvement in scores for physical function, frequency of angina, and quality of life for the first 6 months after randomization, however, this difference was no longer significant after 12 months [23].

Based on the description above, researcher is interested in knowing quality of life comparison for STEMI patients with PCI and non-PCI measures particularly conducted at the Dustira Cimahi Hospital. This research was conducted at Dustira Hospital Cimahi because of the prevalence of CHD in Cimahi City is the third highest and besides handling non-PCI STEMI patients, Dustira Cimahi Hospital as well have a health care facility with PCI procedures.

\section{LITERATURE REVIEW}

\section{A. Acute Coronary Syndrome}

1) Definitions: Acute coronary syndrome (ACS) is a symptom or acute manifestation of plaque atheroma that ruptures or breaks a coronary artery [11]. ACS can occur due to acute myocardial infarction (AMI). IMA is defined as detection increase and / or decrease in cardiac biomarkers that are at least one value at above $99 \%$ of the upper reference limit, accompanied by ischemic symptoms [16,17]. Diagnosis Myocardial infarctions is established if one of the following criteria is met: progression new pathological Q waves on the EKG, or evidence of myocardial infarction on imaging [16].

2) Risk factors: In general, the risk factors for coronary heart disease (CHD) which can cause acute coronary syndrome (ACS) is divided into risk factors that can modified (modified risk factors) and the risk factors cannot be changed (unmodified risk factors) [24-27]. Risk factors that can be changed include habit or bad lifestyle, psychological, and other environmental components [27]. Customs or lifestyle that is not good can be in the form of smoking, inadequate physical activity, dyslipidemia, and obesity, which can cause diseases such as hypertension, Diabetes mellitus (DM) or metabolic syndrome. These diseases are also risk factors that can lead to ACS [26,27]. The irreversible risk factors are family history, gender especially men, and the elderly [26]. Judging from the smoking habit, usually men than women, this also applied to stress levels because most men have work outside. ACS too increases due to the age factor which gradually occurs at the age of 30 up to 50 years. About $55 \%$ of heart attack victims are 65 years or older more [28]. It does not rule out if a young age can experience ACS because there have been several studies examining risk factor profiles and patterns coronary artery involvement especially in patients with ST Segment Elevation Younger myocardial infarction (STEMI) [29].

There are also what are known as novel risk factors such as high sensitive C-Reactive Protein (hsCRP), Lipoprotein-a (Lpa), fibrinogen, homocysteine, apolipoprotein-B (apo-B), and others. Risk factors are previously described can cause atherosclerotic plaque formation. Atherosclerotic plaque can cause damage (necrosis) in the tissue and blood vessels due to the presence of plaques that can suppress the heart work system, which is the etiology or cause of ACS [26,28].

3) Pathophysiology: Most cases of ACS are acute manifestations of atherosclerotic plaques rupture of the coronary artery. The process of atherosclerotic plaque formation begins during early adulthood which develops and grows slowly for decades [30]. As coronary atherosclerosis progresses, these plaques will result in the following coronary artery luminal stenosis with a compensation mechanism namely the collateral canal connecting one the coronary artery with the other becomes enlarged, initially purposeful to allow 
adequate cardiac perfusion during relative inactivity. However, the compensation may not be sufficient for oxygen demand myocardium when the heart needs increased work, such as during strenuous activity [30].

Atherosclerotic plaques are formed due to an inflammatory process in the artery walls against injury to blood vessel cells, namely endothelial cells [10]. After that lipid accumulates on the internal walls of the coronary arteries and forms the basic structure of atherosclerotic plaques consisting of a fibrous cap containing smooth muscle cells tunica intima, macrophages, lymphocytes, collagen, proteoglycans, and neovascularization; and a necrotic center consisting of debris cells, cholesterol crystals, foam cells, and calcium (Figure 1) [10,30].

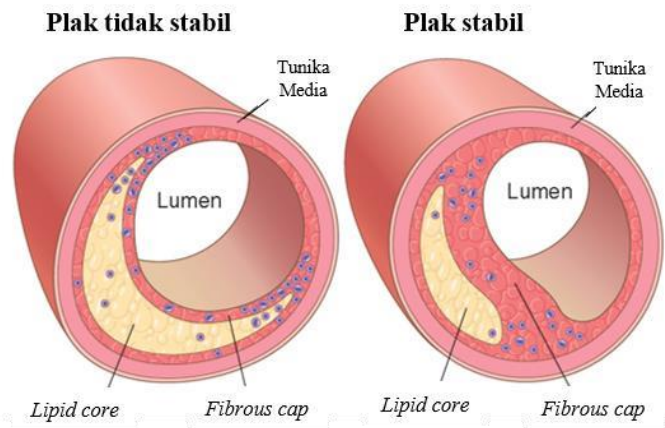

Fig. 1. Basic structure of atherosclerotic plaque [10].

Smooth muscle cells in the tunica intima synthesize the extracellular matrix (MES), especially collagen, which can stabilize atherosclerotic plaque. This stable plaque can cause narrowing of blood vessels therefore causing symptoms associated with chronic ischemia. However, inflammatory cells activated in the plaque can also cause apoptosis (a programmed cell death) in the intima smooth muscle cells and the breakdown of the matrix thus resulting in plaque becoming unstable. Unstable plaques are particularly susceptible to rupture because it has thin fibrous walls, but there is a lot of fat in the middle and dense inflammatory cell infiltrates [10]. If there are changes in plaque composition and thinning of the layer covering the plaque can causing plaque to become acute plaque rupture, thrombus, and embolus $[10,11]$.

If the plaque ruptures, the event will be followed by an aggregation process platelets and activation of the coagulation pathway. A thrombus rich platelet is formed (white thrombus). This thrombus will block the coronary artery lumen, either totally or partially; or become micro embolic clogging more distal coronary vessels. The incident was followed by the occurrence release of vasoactive substances which cause vasoconstriction, thus exacerbating impaired coronary blood flow. Reduced coronary blood flow causes myocardial ischemia. Oxygen supply is stopped for approximately 20 minutes causing the myocardium to experience necrosis (myocardial infarction) [11].
Myocardial infarction is not always the result of total occlusion of the blood vessels coroner. Subtotal obstruction with dynamic vasoconstriction can cause ischemia and necrosis of the heart muscle tissue (myocardium). The result of ischemia, apart from necrosis, is impaired myocardial contractility due to hibernating and stunning processes (after the ischemia is gone), dysrhythmias and ventricular remodeling (change in shape, size and function of the ventricles) [11].

\section{B. ST Segment Elevation Myocardial Infarction (STEMI)}

1) Definitions: ST Segment Elevation Myocardial Infarction (STEMI) is an indicator for incidence of total occlusion of the coronary arteries [11]. STEMI usually occurs when coronary blood flow decreases suddenly after thrombotic occlusion of an artery a coronary previously affected by ruptured atherosclerosis. This injury produced or facilitated by factors such as smoking, hypertension, and accumulation of lipids. In most cases, STEMI occurs when plaque surfaces atherosclerotic rupture and conditions (local or systemic) induced thrombogenesis. The thrombus that forms at the site of the plaque disruption will clog the lumen, causing complete blockage of the coronary artery lumen [31].

2) Diagnosis: ST Segment Elevation Myocardial Infarction (STEMI) can be diagnosed based on history, physical examination, electrocardiogram, and other supporting investigations. Based on the history, STEMI patients experience certain characteristic of chest pain-like pressed, burning, and being crushed by heavy objects mainly on precordial, substernal, and retrosternal. The pain usually radiates to the left arm, and can spread to the neck, lower jaw, teeth, back, and stomach. The trigger factor for chest pain can be due to physical exercise, emotional stress, cold air, and after eating. Pain can be accompanied by symptoms of nausea, vomiting, difficulty breathing, sweating cold, anxious and weak [26].

Physical examination in most of the patients found that the patient looked anxious and restless with pale limbs accompanied by a cold sweat. Patients with symptom substernal chest pain of more than 30 minutes with profuse sweating, then is suspected strong presence of STEMI. An increase in temperature of up to $38^{\circ} \mathrm{C}$ can be seen in weeks first post STEMI [26]. Apart from the history and physical examination, an electrocardiogram is also shown plays an important role in the diagnosis of STEMI. In STEMI patients will show there is a new ST elevation image of more than two millimeters, and at least two V2-V3 headers and or more than one millimeter on the other chest plugs or limb leads. Examination of cardiac enzymes, especially the troponin $\mathrm{T}$ increasing can strengthen the STEMI diagnosis. However, STEMI patients must get reperfusion therapy immediately so there is no need to wait for the results enzyme examination [26]. Therefore, patients with an ECG are diagnostic for STEMI can immediately receive reperfusion therapy. EKG images can also determine the location of myocardial infarction in STEMI patients as in Table 1, as follows [11]: 


\section{Management of ST Segment Elevation Myocardial Infarction (STEMI)}

The main goal of treatment in cases of Myocardial ST Segment Elevation Infarction (STEMI) is to quickly diagnose, relieve chest pain, assess and implement possible reperfusion strategies. Early reperfusion will shorten the length of coronary occlusion, minimizing the degree dysfunction and ventricular dilatation, as well as reducing the chances of a STEMI patient progresses to malignant ventricular pump failure or tachyarrhythmias [26].

The goal of reperfusion therapy is door to needle time to initiate therapy fibrinolytics can be achieved in 30 minutes or door to balloon time for PCI can be reached in 90 minutes $[26,32,33]$. Effectiveness of fibrinolytic drugs in destroying time dependent thrombus. Fibrinolytic therapy given within two hours first (especially in the first hour) can stop myocardial infarction and lowering the mortality rate [26].

The choice of reperfusion therapy can involve the risk of bleeding in the patient. If concomitant reperfusion therapy (PCI and fibrinolytic available), the higher the risk bleeding with fibrinolytic therapy, the stronger the decision to choose PCI. If PCI is not available, then pharmacological reperfusion therapy should be considered, including the benefits and risks [26].

The goal of managing patients with suspected STEMI is to reduce or eliminate chest pain and should be identified quickly for the handling of reperfusion which can be done as in Figure 2. Line arrows and bold squares in the figure indicate which strategy is preferred for handling STEMI cases. If the patient will be carried out angiography and should not be attempted within two to three hours of revascularization fibrinolytic therapy $[11,26]$.

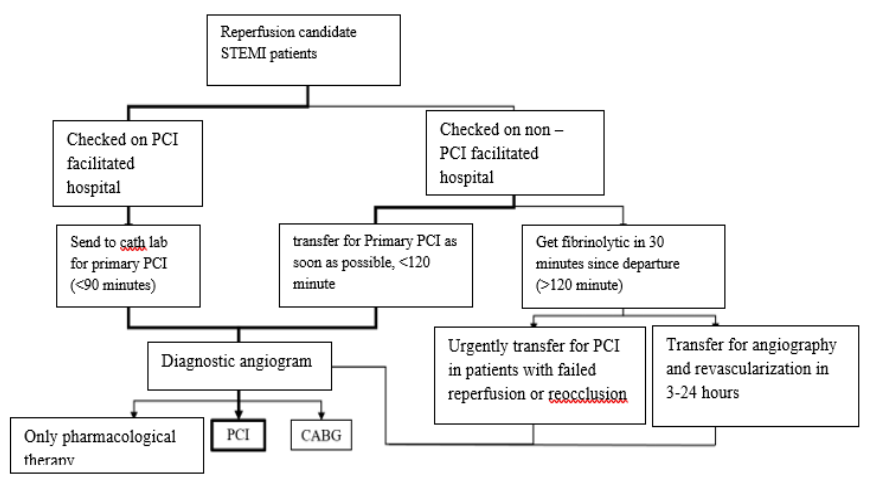

Fig. 2. Reperfusion therapy in STEMI patients [26].

\section{1) Percutaneous Coronary Intervention (PCI) measures}

a) Definition: Percutaneous Coronary Intervention (PCI) or Percutaneous Coronary Intervention (IKP) is a non-surgical intervention using catheters coronary, whether or not followed by stenting to dilate or open narrowed coronary vessels, as in Figure 3. 8.19 The narrowing of the coronary vessels can be caused by the process atherosclerosis or thrombosis [8].
Patients with CHD with the STEMI type should immediately undergo coronary angiography, after identifying the blocked coronary arteries then proceed with attempt to open the blockage by inserting a guide wire from metal for the thrombus plug. After that, it is expanded with a balloon and if necessary, put a stent. If there are too many clogged lumps it can aspirated first using an aspiration catheter before being ballooned or installed a stent [19].

The primary PCI action creates patent lumens extensively, resulting in on most patients do not develop significant residual stenosis at the site of occlusion artery associated infarction. Lack of incidence of stenosis after PCI causes the incidence of recurrent ischemia and re-occlusion of the associated infarct artery is lower. The incidence of re-occlusion in the associated arterial infarction after PCI primary is only $9 \%$ to $16 \%$ and this figure has reduced to around 5\% after the appearance of $a$ coronary stent [34].

Coronary stent installation effectively can make postprocedural diameter measures wider compared to post PCI using balloons only. Stent installation initially avoided for AMI patients because of concerns about the risk of thrombotic stents but seen from the importance of optimal stent dispersion and effective inhibition platelets, it's recognized that primary PCI with bare metal stents (BMS) is feasible to use. Stent installation of Coronary to improve initial and final yield after mechanical reperfusion is quite promising [34].

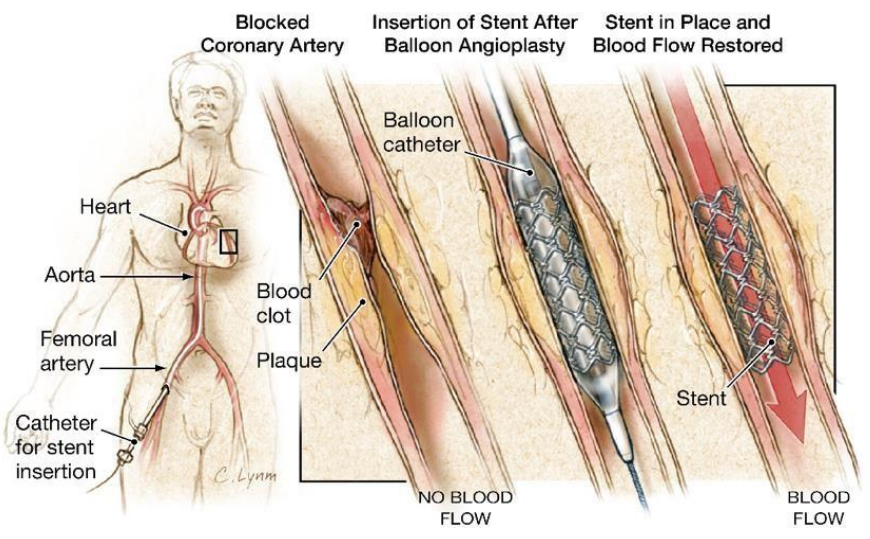

Fig. 3. Stenting a previously blocked coronary artery [19].

b) Indication: Percutaneous Coronary Intervention (PCI) (angioplasty or stenting) without preceded fibrinolytic is called primary PCI (primary PCI). Effective PCI measures in restoring perfusion to STEMI if done the first few hours acute myocardial infarction. Primary PCI is more effective than fibrinolytic in opening arteries coronary obstruction associated with short-term clinical outcome and the better long term [26,31].

Percutaneous Coronary Intervention is preferred if there is shock cardiogenic (especially in patients less than 75 years), risk of bleeding increase, or symptoms have been present for at least two or three hours if the clot the blood is more mature and less easily destroyed with fibrinolytic drugs. However, PCI 
more expensive in terms of personnel and facilities, and limited application based on the availability of facilities, only in a few hospitals [26,31]. In addition to the already cases mentioned, another indication for PCI is acute high-risk NSTEMI (using early PCI), and CHD (significant coronary artery stenosis) [8].

c) Contraindications: Revascularization measures with Percutaneous Coronary Intervention generally there is no absolute because the response will be different from each patient. Several factors may be relevant depending on the consideration's family history, work needs, and lifestyle of the individual. However, there is a number of relative contraindications have been reported [35]. Such contraindications consist of kidney failure, especially patients with a history of diabetes, hemorrhage, stroke, anaphylactic shock reactions, thrombosis, and pericardial effusion [8,35].

2) Measures other than Percutaneous Coronary Intervention (Non-PCI): Measures other than Percutaneous Coronary Intervention (Non-Percutaneous Coronary Intervention) in STEMI patients can be in the form of surgical interventions such as Coronary Artery Bypass Grafting (CABG) or therapy can be used pharmacological. CABG action is done by creating a new channel through a narrowed or blocked coronary artery. Action $\mathrm{CABG}$ requires quite a long time about 3 - 6 hours [11,26,30,31].

Pharmacological therapy that is most appropriate for STEMI patients is therapy fibrinolytic. Fibrinolytic therapy is preferably administered within 30 minutes of admission (door to needle time less than 30 minutes) if there are no contraindications. Destination the main thing is to quickly restore the patency of the coronary arteries. There are several kinds of fibrinolytic drugs, including tissue plasminogen activator (tPA), streptokinase, tenecteplase (TNK), reteplase (rPA), which act by inducing conversion of plasminogen to plasmin which will lyse fibrin thrombus [26,31].

Flow within the involved coronary arteries was described on a qualitative scale simple by angiography, called thrombolysis in myocardial infarction (TIMI) grading system [36,37]:

- Grade 0 indicates complete occlusion of the artery had an infarction.

- Grade 1 indicates the penetration of some of the contrast material past the point obstruction but without distal vascular perfusion.

- Grade 2 indicates distal perfusion of the infarcted vessel but with a flow that is slower than normal arterial flow.

- Grade 3 indicates full perfusion of the vessel infarcted with normal flow.

Thrombolysis in myocardial infarction (TIMI) has become the benchmark for assess the increase in reproducibility of coronary blood flow angiography and for assess the microvascular perfusion of that portion of the left ventricle in the distribution area of the artery occluded [36]. The target of reperfusion therapy is TIMI grade 3 flow due to full perfusion in the coronary arteries affected by the infarction showed a better outcome limit the extent of infarction, maintain left ventricular function, and decrease mortality rate [26].

Other drugs that can be given to STEMI patients besides fibrinolytics, namely anticoagulants, but anticoagulant therapy should be added to antiplatelet therapy as soon as possible. Anticoagulant administration is recommended for all patients who are getting antiplatelet therapy. The choice of anticoagulant is made on the basis of risk bleeding and ischemia and based on the efficacy - safety profile of these agents [11].

a) Contraindications: Relative contraindications for fibrinolytic therapy in STEMI consist of bleeding diathesis (severe thrombocytopenia, coagulopathy) or flow used in anticoagulants, previously given streptokinase treatment for past six to nine months (in which cases rt- PA), blood pressure of $180 / 100 \mathrm{mmHg}$ or more at less than two times examination, active peptic ulcer disease, history of cerebrovascular events thrombotic, CPR that is longer than 10 minutes or traumatic $\mathrm{CPR}$, retinopathy diabetic hemorrhagic or other hemorrhagic ophthalmic conditions, and pregnancy [38].

\section{Quality of Life in STEMI Patients}

1) Definition of quality of life: According to WHO, quality of life is an individual's perception of position life in the context of culture and assessment systems in the environment they live and relate to goals, expectations, and standards. That matter is a broad concept that can be complex in terms of health one's physical, psychological state, personal beliefs, and social relationships [20]. Quality of life in STEMI patients can be measured using the Seattle instrument Angina Questionnaire (SAQ) [21].

2) Seattle Angina Questionnaire (SAQ): The Seattle Angina Questionnaire (SAQ) is an instrument for disease specifics that have been widely used. This questionnaire was developed in America States to measure the physical and emotional effects associated with angina in CHD patients and has been cross-culturally adapted for use in 13 countries, including English [39]. This questionnaire is a benchmark for someone to run various kinds of activities according to ability, seen from various aspects which reflects the quality of life of the person [22].

Seattle Angina Questionnaire (SAQ) is prepared with a questionnaire consisting of several clinical scales or dimensions, namely physical activity, pain frequency, stability pain, patient satisfaction and patient perception of disease [21]. Research results previously demonstrated that the SAQ is a valid measure of quality of life in patients with Acute Coronary Syndrome (ACS) [40].

This questionnaire can also determine the quality of life of STEMI type ACS patients after reperfusion measures, namely 
PCI and non-PCI measures. Action PCI also provides greater patient quality of life improvements symptoms of angina and exercise tolerance, as well as lowering the need for medicationmedicine when compared to pharmacological (non-PCI) therapy [18].

Scores on the Seattle Angina Questionnaire (SAQ) range from 0-100 with specifies each response as an ordinal value, starting with one for the response indicating the lowest level of functionality, and sums up the whole items in each scale. The scale score is then converted into a range of $0-100$ by subtracting the lowest scale score, then dividing by range these scales and multiply by 100 . Each scale monitors unique dimensions of coronary artery disease so there is no summary score generated [22]

Calculation scoring SAQ is integrally standards can be formulated as in the following, standard integral $=$ (actual score - lowest score of each item) / (highest score of each item - the lowest score for each item) $\times 100$. The higher the score, the better the quality of life and physical function of the patient $[22,41]$.

a) Physical activity: Physical activity is the movement of the body due to the skeletal muscles resulting in energy expenditure. Physical activity in SAQ is abilities that can be performed by STEMI patients after reperfusion both using PCI and Non-PCI are subject to several limitations which is divided into severe limitation (weight limitation), moderate limitation (moderate limitation), mild limitation, and slight to no limitation (little or no limit) [22].

b) Frequency of pain: The frequency of pain is a feeling of discomfort, both mild and severe or it can be interpreted as a situation that affects a person and its existence is known if someone has experienced it. Pain can be felt by STEMI patients after PCI and Non-PCI and how often the frequency of pain experienced by each patient will be different. The frequency of pain felt by the patient is categorized into always, often, sometimes, rarely, and almost never [22].

The frequency of pain is always said if the patient feels more than chest pain three times per day, often if the patient has between one and three chest pain times per day, sometimes if the patient feels chest pain more than twice per week, rarely if the patient has chest pain only one to two times per week and said never if the patient only feels chest pain for the last four weeks [22].

c) Satisfaction with treatment, explanation, and treatment: Satisfaction or satisfaction is the main indicator of the standard of a facility health and is a measure of the quality of health service satisfaction as well interpreted as feeling happy or disappointed from someone who gets an impression from the results of service performance with its expectations. The patient will feel satisfied to several things as well as according to the SAQ patient satisfaction after PCI and NonPCI, including patient satisfaction with the treatment of personnel health, doctor's explanation, and medication when dealing with chest pain, tightness chest, or angina [22].

3) Comparison of quality of life for STEMI patients who underwent PCI with non-PCI: Scores on the Seattle Angina Questionnaire (SAQ) range from $0-100$ and if scores the higher the obtained, the more the indication of his health status getting better [22,23]. The score increased in the patient group performed PCI measures in comparison with non-PCI. Among patients with angina is stable, those with PCI and Non-PCI alone have experienced it increase in health status while still getting further action. The PCI family has an additional, but more significant, benefit [23].

PCI action which is a percutaneous revascularization action (with or without stenting) was compared with fibrinolysis in 23 randomized trials [42]. The data from these trials indicate that the result of PCI action occurred an approximate $25 \%$ reduction in mortality, a $64 \%$ reduction in reinfarction, $95 \%$ reduction in intracranial bleeding, and 53\% reduction in stroke. The main reason the reperfusion action benefits from normal blood flow arterial-associated infarction accounts for $90-95 \%$ of patients with primary PCI, however only $50-60 \%$ of patients treated with fibrinolytic drugs $[42,43]$.

The reduction in mortality with primary PCI is probably explained by atherosclerotic plaque breakdown mechanisms resulting in embolization and recurrent infarction is reduced. The fibrinolysis drug has successfully resolved the thrombus but did not immediately resolve the ruptured plaque. The effectiveness of fibrinolytic drugs as well will decline rapidly with time from symptom onset beyond two hours. Necropsy studies show that injuries re-perfuse and transform hemorrhagic myocardial infarction often follows fibrinolytic therapy [43].

Based on the results of research by Weintraub [23], during the period advanced treatment in patients with stable angina, the percentage of patients who are free of angina significantly higher in the PCI group than in the therapy group medical for 24 months, which is about $53 \%$, but not significantly different between the two groups at 36 months. Larger proportion of the group PCI had a clinically significant improvement in physical function scores, frequency of angina, and quality of life for the first 6 months after randomization, however, this difference was no longer significant after 12 months [23]. According to research Cohen et al. [44], at one month after PCI, scores on the subscale physical activity, quality of life, and patient satisfaction were quite high in the group by which PCI measures are performed.

\section{E. Framework}

Acute coronary syndrome (ACS) occurs due to the presence of atherosclerotic plaques blood vessels, especially the coronary arteries, which grow slowly with age, 12 which will gradually cause symptoms myocardial ischemia to heart attack (myocardial infarction) [9]. Total occlusions in the coronary 
arteries will cause acute myocardial infarction with ST segment elevation (STEMI) [11].Some patients choose reperfusion treatment with revascularization using Percutaneous Coronary insertion Intervention (PCI). Some patients also choose reperfusion therapy with Non-PCI (pharmacological therapy) [11].

The two treatments have differences in quality change life after being given the treatment. Changes in the quality of life can be seen from physical activity, pain frequency, pain stability, patient satisfaction and patient perceptions of disease [21]. These measures of quality of life can be measured through the Seattle Angina Questionnaire (SAQ) [22]. Therefore, at this study will look at the comparison of the quality of life of STEMI patients PCI was performed with NonPCI at Dustira Cimahi Hospital (Figure 4).

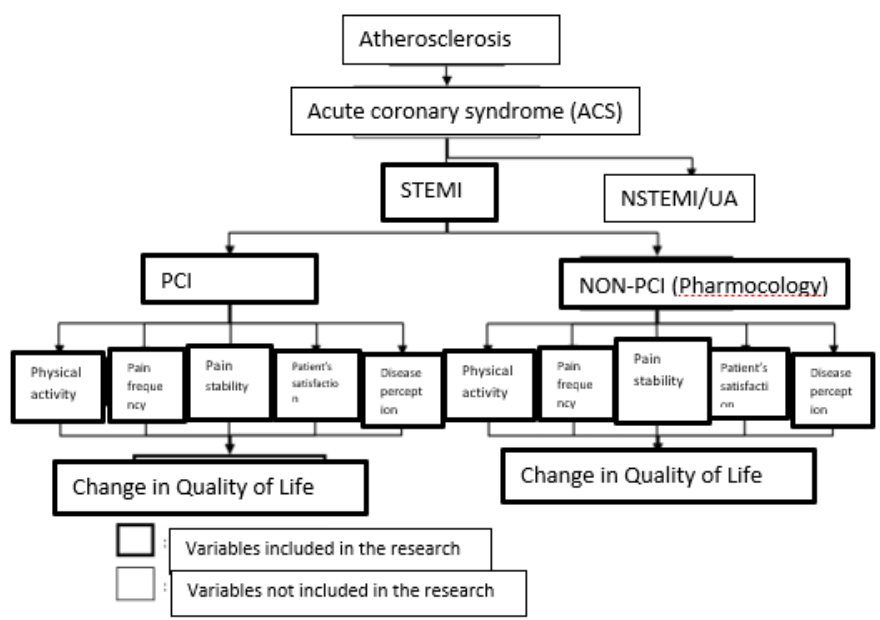

Fig. 4. Research framework.

\section{F. Premise}

The premise of this research is:

- STEMI occurs due to total occlusion of the coronary arteries [11].

- STEMI must be treated with immediate reperfusion with the aim to accelerate the flow of narrowed coronary blood, which can either PCI or non-PCI action $[11,18,26]$.

- Actions PCI is an act of reperfusion of coronary blood vessels with nonsurgical interventional procedures using a catheter to dilate or opening narrowed coronary vessels with a balloon or stent [8]. Flow normal blood in the associated infarct artery reaches $90-95 \%$ of patients with PCI, so that network reperfusion is getting better again $[26,42,43]$.

- Non-PCI measures are actions other than coronary artery reperfusion One of the actions of PCI can be in the form of pharmacological therapy with fibrinolytic [26,31]. Blood flow becomes normal in the infarct- associated artery only up to $50-60 \%$ in patients treated with fibrinolytic drugs, so that allowing reperfusion to each network is insufficient $[26,42,43]$.

- The Seattle Angina Questionnaire (SAQ) is a measure that can used to measure the quality of life of STEMI patients who have been done PCI and non-PCI measures, as measured by physical activity, pain frequency, pain stability, patient satisfaction, and perception of disease $[18,19,22,40]$

- The mechanism of coronary vessel dilation in PCI causes tissue reperfusion again improved immediately compared with non-PCI measures, which can affect physical activity, pain frequency, and pain stability in STEMI patients

\section{G. Hypothesis}

The hypothesis in this study is the quality of life as measured by SAQ in STEMI patients after PCI was better than with STEMI patients who underwent non-PCI procedures.

\section{RESEARCH METHODS}

\section{A. Research Design}

The design used in this research was comparative analytic with a cross sectional study approach. Researchers took primary data from questionnaires distributed and filled out by STEMI patients to determine the comparison of the quality of life of STEMI patients who were treated with PCI and NonPCI at Dustira Cimahi Hospital.

\section{B. Research Subjects}

1) Population: The study population was patients with STEMI who do control to Cardiology clinic in Dustira Cimahi Hospital from October to December .

\section{Number of Samples}

1) Large sample: The number of samples in this study were part of the population that met the sample criteria. A large sample of the research is determined by using the formula unpaired categorical variables as follows:

$$
n=\frac{\left\{Z_{1-\alpha / 2} \sqrt{2 P(1-P)+Z_{1-\beta} \sqrt{ } P_{1}\left(1-\overline{\left.\left.P_{1}\right)+P_{2}\left(1-P_{2}\right)\right\}}\right.}{ }^{2}\right.}{\left(P_{1-P_{2}}\right)^{2}}
$$

Information:

n: Sample size

Z 1- $\alpha$ / 2: Standard deviation of alpha and $Z$ values taken from normal distribution table for $95 \%$ confidence interval

\section{Z 1- $\beta$ : Power}

P: Proportion of variable categories under study 
P 1: Proportion of the incidence of STEMI patients undergoing PCI

P 2: Proportion of the incidence of STEMI patients who underwent non-PCI procedures

From the calculations above, it was found that the sample size studied was 17 people in each group (STEMI patients with PCI and STEMI patients with non-PCI measures), so that the total number of samples needed in the study was 34 people.

\section{Research Instruments}

The instrument or data collection tool used in this study was a questionnaire. The research questionnaire used refers to the Seattle Angina Questionnaire (SAQ). The research questionnaire was in the form of multiple choice questions to be filled out by STEMI patients at Dustira Cimahi Hospital. The questionnaire consisted of 17 questions describing the quality of life of STEMI patients after PCI and non-PCI. The first to the ninth question is a question that describes the quality of life of patients based on physical activity, tenth and eleventh questions illustrate the frequency of pain, the question of the 12 th and 13th illustrate the stability of pain, the question 14 to 16 measure the level of patient satisfaction, and the 17 th question is the patient's perception of the disease.

Scores on the Seattle Angina Questionnaire (SAQ) range from 0-100 by assigning each response an ordinal value, starting with one for the response indicating the lowest level of functioning. The SAQ scoring calculation can be formulated by the sum of each category. Each scale monitors the unique dimensions of coronary artery disease so that no summary score is generated. The more high outcome scores were obtained, then more and better quality of life and physical function of patients $[22,40]$.

\section{RESUlTS AND DisCUSSION}

\section{A. Research Results}

Results obtained from questionnaires completed by patients at the Clinic Heart Hospital STEMI Dustira Cimahi in October 2018 and December 2018. The number of samples obtained was 17 STEMI patients who underwent PCI after three months to one year and 17 Non-PCI STEMI patients after four months to a year.

The results of the respondents' quality of life were measured using the Seattle Angina Questionnaire (SAQ) which consists of five clinical dimensions, namely physical activity, pain frequency, pain stability, patient satisfaction, and patient perceptions of disease. The physical activity measured was obtained from nine categories, namely wearing clothes, walking back and forth, taking a shower, climbing stairs, cleaning the house, walking, jogging, lifting things, and exercising. The frequency of pain is divided into two categories, the frequency of pain that occurred in the past month and drug consumption when chest pain occurs. Stability of pain was measured from what is perceived by the patient and the patients' ability to daily activities. Patient satisfaction is measured from three categories, respondent satisfaction with the treatment obtained by medical personnel, doctor's explanation, and treatment given at Dustira Cimahi Hospital.

An overview of the quality of life of STEMI patients based on physical activity categories is described in Table 1 . Table 1 describes the results of the analysis of the quality of life for respondents who have performed PCI action compared to nonPCI based on physical activity categories, as follows:

TABLE I. AN OVERVIEW OF THE QUALITY OF LIFE OF STEMI PATIENTS ON PHYSICAL ACTIVITY

\begin{tabular}{|c|c|c|c|c|}
\hline \multirow{3}{*}{ Variable } & \multicolumn{4}{|c|}{ Reperfusion therapy } \\
\hline & \multicolumn{2}{|c|}{$P C I$} & \multicolumn{2}{|c|}{ Non-PCI } \\
\hline & $n$ & $\%$ & $n$ & $\%$ \\
\hline \multicolumn{5}{|l|}{ Physical Activity } \\
\hline \multicolumn{5}{|l|}{ Putting on clothes } \\
\hline Moderate limitations & 0 & 0.0 & 1 & 5.8 \\
\hline Mild limitation & 3 & 17.6 & 5 & 29.4 \\
\hline There are no limitations & 14 & 82.3 & 1 & 64.7 \\
\hline \multicolumn{5}{|l|}{ Walk back and forth } \\
\hline Severe limitations & 0 & 0.0 & 1 & 5.8 \\
\hline Moderate limitations & 1 & 5.8 & 3 & 17.6 \\
\hline Mild limitation & 4 & 23.5 & 2 & 70.5 \\
\hline There are no limitations & 12 & 70.5 & 1 & 5.8 \\
\hline \multicolumn{5}{|l|}{ Bath } \\
\hline There are no limitations & 17 & 100.0 & 7 & 100 \\
\hline \multicolumn{5}{|l|}{ Climbing up the stairs } \\
\hline Severe limitations & 0 & 0.0 & 1 & 5.8 \\
\hline Moderate limitations & 1 & 5.8 & 9 & 52.9 \\
\hline Mild limitation & 6 & 35.2 & 7 & 41.1 \\
\hline There are no limitations & 10 & 58.8 & 0 & 0.0 \\
\hline \multicolumn{5}{|l|}{ Cleaning the house } \\
\hline Moderate limitations & 0 & 0.0 & 8 & 47.0 \\
\hline Mild limitation & 7 & 41.1 & 8 & 47.0 \\
\hline There are no limitations & 10 & 58.8 & 1 & 5.8 \\
\hline \multicolumn{5}{|l|}{ Walk } \\
\hline Severe limitations & 0 & 0.0 & 1 & 5.8 \\
\hline Moderate limitations & 1 & 5.8 & 3 & 17.6 \\
\hline Mild limitation & 3 & 17.6 & 2 & 70.5 \\
\hline There are no limitations & 13 & 76.4 & 1 & 5.8 \\
\hline \multicolumn{5}{|l|}{ Run small } \\
\hline Severe limitations & 0 & 0.0 & 1 & 5.8 \\
\hline Moderate limitations & 1 & 5.8 & 8 & 47.0 \\
\hline Mild limitation & 6 & 32 & 8 & 47.0 \\
\hline There are no limitations & 10 & 58.8 & 0 & 0.0 \\
\hline \multicolumn{5}{|l|}{$\begin{array}{c}\text { Lifting goods } \\
\end{array}$} \\
\hline Moderate limitations & 0 & 0.0 & 2 & 11.7 \\
\hline Mild limitation & 2 & 11.7 & 2 & 70.5 \\
\hline There are no limitations & 15 & 88.2 & 3 & 17.6 \\
\hline \multicolumn{5}{|l|}{ Sports } \\
\hline Severe limitations & 0 & 0.0 & 1 & 5.8 \\
\hline Moderate limitations & 1 & 5.8 & 0 & 58.8 \\
\hline Mild limitation & 7 & 41.1 & 6 & 35.2 \\
\hline There are no limitations & 9 & 52.9 & 0 & 0.0 \\
\hline
\end{tabular}

An overview of the quality of life of STEMI patients based on pain frequency categories is described in Table 2. Table 2 describes the results of the analysis of the quality of life description of respondents who have been treated with PCI 
compared to Non-PCI based on the frequency of pain categories, as follows:

TABLE II. OVERVIEW STEMI PATIENT QUALITY OF LIFE AT A FREQUENCY OF PAIN

\begin{tabular}{|l|c|c|c|c|}
\hline \multirow{2}{*}{ Variable } & \multicolumn{4}{c|}{ Reperfusion therapy } \\
\cline { 2 - 5 } & \multicolumn{3}{|c|}{ PCI } & Non-PCI \\
\cline { 2 - 5 } & $\boldsymbol{n}$ & $\boldsymbol{\%}$ & $\boldsymbol{n}$ & $\%$ \\
\hline \multicolumn{1}{|c|}{ Pain Frequency } & & & & \\
\hline Sometimes frequency & & & & \\
\hline Rarely & 1 & 5.8 & 5 & 29.4 \\
\hline Almost never & 1 & 5.8 & 4 & 23.5 \\
\hline Never & 6 & 35.2 & 8 & 47.0 \\
\hline Take medication for pain & 9 & 52.9 & 0 & 0.0 \\
\hline Sometimes & 1 & & & \\
\hline Rarely & 1 & 5.8 & 4 & 23.5 \\
\hline Almost never & 6 & 35.2 & 8 & 47.0 \\
\hline Never & 9 & 52.9 & 0 & 0.0 \\
\hline
\end{tabular}

An overview of the quality of life of STEMI patients based on the pain stability category is described in Table 3 , Table 3 describes the results of the analysis of the quality of life description of respondents who have performed PCI compared to Non-PCI based on the frequency category of pain seen from the pain felt by the respondent and the respondent's survival, as follows:

TABLE III. AN OVERVIEW OF THE QUALITY OF LIFE OF STEMI PATIENTS ON PAIN STABILITY

\begin{tabular}{|l|c|c|c|c|}
\hline \multirow{2}{*}{ Variable } & \multicolumn{4}{c|}{ Reperfusion therapy } \\
\cline { 2 - 5 } & \multicolumn{2}{|c|}{$\boldsymbol{P C I}$} & Non-PCI \\
\cline { 2 - 5 } \multicolumn{1}{|c|}{ Pain Stability } & $\boldsymbol{n}$ & & & \\
\hline \multicolumn{1}{|c|}{ That is felt } & & & & \\
\hline It got really bad & 0 & 0.0 & 1 & 5.8 \\
\hline It gets worse & 1 & 5.8 & 2 & 11.7 \\
\hline Do not change & 2 & 11.7 & 12 & 70.5 \\
\hline Get better & 11 & 64.7 & 2 & 11.7 \\
\hline Very much improved & 3 & 17.6 & 0 & 0.0 \\
\hline \multicolumn{1}{|c|}{ Life sustainability } & & & & \\
\hline It got really bad & 0 & 0.0 & 1 & 5.8 \\
\hline It gets worse & 1 & 5.8 & 2 & 11.7 \\
\hline Do not change & 2 & 11.7 & 3 & 76.4 \\
\hline Get better & 13 & 76.4 & 1 & 5.8 \\
\hline Very much improved & 1 & 5.8 & 0 & 0.0 \\
\hline
\end{tabular}

The description of the quality of life of STEMI patients in the patient satisfaction category is described in Table 4. Table 4 describes the results of the analysis of the quality of life description of respondents who have performed PCI action compared to Non-PCI based on the category of patient satisfaction with medical personnel treatment, doctor's explanation, and treatment at Dustira Cimahi Hospital, as follows:
TABLE IV _ DESCRIPTION OF THE QUALITY OF LIFE OF STEMI PATIENTS ON PATIENT SATISFACTION

\begin{tabular}{|c|c|c|c|c|}
\hline \multirow{2}{*}{ Variable } & \multicolumn{4}{|c|}{ Reperfusion therapy } \\
\cline { 2 - 5 } & \multicolumn{3}{|c|}{ PCI } & Non-PCI \\
\cline { 2 - 5 } & $\boldsymbol{n}$ & $\boldsymbol{n}$ & $\boldsymbol{n}$ \\
\hline Patient Satisfaction & & & & \\
\hline Treatment of health workers & & & 1 & 5.8 \\
\hline Not satisfied & 0 & 0.0 & 14 & 82.3 \\
\hline Satisfied & 14 & 82.3 & 2 & 11.7 \\
\hline Very satisfied & 3 & 17.6 & & \\
\hline Doctor's explanation & & & & 82.3 \\
\hline Satisfied & 7 & 41.1 & 14 & 17.6 \\
\hline Very satisfied & 10 & 58.8 & 3 & \\
\hline Treatment & & & & 100 \\
\hline Satisfied & 6 & 35.2 & 17 & 0.0 \\
\hline Very satisfied & 11 & 64.7 & 0 & \\
\hline
\end{tabular}

An overview of the quality of life of STEMI patients in the perception category of disease is described in Table 5, as follows:

TABLE V. DESCRIPTION OF THE QUALITY OF LIFE OF STEMI PATIENTS ON THE PERCEPTION OF DISEASE

\begin{tabular}{|c|c|c|c|c|}
\hline \multirow{3}{*}{ Variable } & \multicolumn{4}{|c|}{ Reperfusion therapy } \\
\hline & \multicolumn{2}{|c|}{$P C I$} & \multicolumn{2}{|c|}{ Non-PCI } \\
\hline & $n$ & $\%$ & $n$ & $\%$ \\
\hline \multicolumn{5}{|l|}{ Perception of disease } \\
\hline Often & 1 & 5.8 & 3 & 17.6 \\
\hline Sometimes & 3 & 17.6 & 10 & 58.8 \\
\hline Rarely & 8 & 47.0 & 4 & 23.5 \\
\hline Never & 5 & 29.4 & 0 & 0.0 \\
\hline
\end{tabular}

\section{B. Discussion}

1) Overview of the quality of life of STEMI patients with PCI action at Dustira Cimahi Hospital: Table 1 shows an overview of the quality of life of STEMI patients with PCI action at Dustira Cimahi Hospital, it was found that on average some respondents with PCI did not experience limitations in physical activity wearing clothes $(82.3 \%)$, walking back and forth (70.5\%), take a shower (100.0\%), climb the stairs $(58.8 \%)$, cleaning the house $(58.8 \%)$, walking $(76.4 \%)$, jogging $(58.8 \%)$, lifting goods $(88.2 \%)$, and sports $(52.9 \%)$. The results of this study are almost the same as the results of the study by Cohen et al. [44], Which showed that the score on the physical activity subscale was quite high in the group that had been treated with PCI. This can be explained in theory that the plaque breakdown mechanism atherosclerotic on PCI action that resulted in the opening of the coronary arteries are clogged in the above $90 \%$ so that the flow of blood back smoothly. Blood flow that returns smoothly causes reperfusion to the tissues throughout the body to improve again so that physical activity tends not to experience limitations [19,26,43,44].

Based on Table 2, the results of the analysis of quality of life measured by the frequency of pain after the act of PCI found most respondents have never felt pain in the chest in the 
last month $(52.9 \%)$, so that the drugs for pain chest was never taken $(52,9 \%)$. The results of this study are almost the same as the results of previous studies which state that myocardial revascularization with PCI is more effective in relieving angina during follow-up treatment both in the short and long term [24].

Based on the analysis in Table 3 obtained the majority of respondents who have performed acts PCI feel better $(64.7 \%)$, and in the category of continuity of life of respondents who have carried out acts PCI feel better $(76,4 \%)$. The results of this study are similar to those of previous studies that showed that myocardial revascularization with PCI was more effective in relieving angina, reducing the use of antianginal drugs, and increasing survival as long as it was accompanied by follow-up treatment both in the short and long term [24].

Table 4 shows the results of the analysis of quality of life as measured by patient satisfaction with the treatment of health workers at Dustira Cimahi Hospital with PCI. It was found that most of the respondents were satisfied $(82.3 \%)$. Respondents satisfaction with the doctor's explanation was found that most of the respondents were very satisfied $(58,8 \%)$. Most large respondents who have carried out act of PCI was very satisfied with the treatment in hospital Dustira Cimahi (64.7\%). The results of this study are almost the same as the results of the study by Cohen et al., which showed that at one month after the PCI procedure, the score on the patient satisfaction subscale was quite high in the group that was treated with PCI [44].

The results of the analysis in Table 5 show an overview of the quality of life measured from the patient's perception of disease after PCI. It was found that most respondents rarely worried about the possibility of a heart attack (47.0\%). In theory, it is explained that the mechanism of atherosclerotic plaque breakdown in PCI results in more than $90 \%$ of clogged coronary arteries opening so that blood flow returns smoothly. By because the patient who has done PCI actions tend to be less worrisome heart attack back $[19,43]$.

2) Description of quality of life for STEMI patients with non-PCI measures at Dustira Cimahi Hospital: Based on Table 1 which shows an overview of the quality of life of STEMI patients with Non-PCI measures at Dustira Cimahi Hospital, it was found that on average some STEMI patients with Non-PCI measures did not experience limitations in physical activity wearing clothes $(64.7 \%)$ and bathing $(100,0 \%)$, whereas in physical activity, walking back and forth and walking experienced mild limitations as much as $70.5 \%$. Some respondents experienced moderate limitations in the category of physical activity climbing stairs as much as $52.9 \%$, the category of physical activity cleaning the house and jogging, some respondents experienced mild to moderate limitations as much as $47.7 \%$ and some respondents experienced moderate limitations in physical activity sports by $58,8 \%$.
According to previous studies, pharmacological therapy can cause normal blood flow in the associated infarct arteries but only in 50-60\% [42]. This can be explained in theory that pharmacological therapies for STEMI patients such as fibrinolytic drugs are successful in resolving the thrombus, but do not immediately resolve the ruptured plaque. The effectiveness of fibrinolytic drugs also decreases rapidly as the time from symptom onset exceeds two hours, which can affect blood flow to the tissues. The less than optimal blood flow to the tissues throughout the body will affect the physical activity of the patient so that patients who undergo non-PCI procedures tend to experience limitations in physical activity $[26,42,43]$.

Based on Table 4, the results of the quality of life analysis are measured from patients satisfaction with the treatment of health workers at Dustira Cimahi Hospital with Non-PCI measured were satisfied $(82,3 \%)$. Patients satisfaction with the doctor's explanation at the Dustira Cimahi Hospital for respondents who had taken non-PCI measures who felt satisfied was $82,3 \%$. Most of the respondents who had non-PCI measure were satisfied with the treatment at Dustira Cimahi Hospital as much as $100,0 \%$.

The results of the analysis in Table 5 show a picture of the quality of life measured from the patient's perception of the disease after non-PCI measures. Sometimes they worry about the possibility of a heart attack, there is $58.8 \%$. According to previous studies, pharmacological therapy can cause normal blood flow in the associated infarct arteries but only reaches $50-60 \%$ [42]. This can be explained in theory that pharmacological therapies for STEMI patients such as fibrinolytic drugs are successful in resolving the thrombus, but do not immediately resolve the ruptured plaque.

The effectiveness of fibrinolytic drugs also decreases rapidly as the time from symptom onset exceeds two hours, which can affect blood flow to the tissues. Less blood flow to tissues throughout the body, especially in the heart muscle, can cause another heart attack. Necropsy studies have shown that the onset of reperfusion injury and haemorrhagic transformation of myocardial infarction is common after fibrinolytic therapy. Therefore, STEMI patients who undergo non-PCI procedures tend to worry about another heart attack $[26,43]$.

3) Comparison of the quality of life of STEMI patients who underwent PCI and non-PCI measures at Dustira Cimahi Hospital: The results showed that STEMI patients who have undergone PCI and non-PCI procedures have differences in each clinical dimension of quality of life after treatment. Based on the results analysis in Table 1 shows that in physical activity such as wearing clothes, it was found that most of the respondents who had done PCI did not experience limitations was $82.3 \%$, while respondents with Non-PCI measures did not experience limitations was $64.7 \%$. Most of the respondents who had done PCI did not experience limitations in walking back and forth $(70.5 \%)$, while respondents who had non-PCI had mild limitations in walking back and forth was $70.5 \%$. 
Respondents who have received both PCI and nonPCI measures do not experience limitations in physical activity for bathing $(100.0 \%)$. In the category of physical activity climbing stairs, it was found that most of the respondents who had done PCI had no limitations in climbing stairs $(58.8 \%)$, while respondents who took non-PCI had moderate limitations in climbing stairs as much as $52.9 \%$.

In the category of physical activity cleaning the house, most of the respondents who had done PCI were found not to have any limitations as much as $58.8 \%$, while respondents who had been doing non-PCI had mild-moderate limitations in cleaning the house as much as $47.0 \%$. In the category of physical activity walking, it was found that most of the respondents who had done PCI had no limitations in walking $(76.4 \%)$, while respondents who had taken non-PCI had mild limitations in walking as much as $70.5 \%$. Most of the respondents who had PCI action did not experience limitations in physical activity for jogging (58.8\%), while respondents with non-PCI measures experienced mild-moderate limitations in physical activity for jogging as much as $47.0 \%$.

Based on Table 2, the results of the quality of life analysis measured from the frequency of pain with reperfusion therapy found that most of the respondents who had undergone PCI had almost never felt pain in the chest $(52.9 \%)$, so that they never took drugs during chest pain $(52,9 \%)$. Respondents with nonPCI procedures sometimes felt chest pain and took medication for chest pain as much as $29.4 \%$.

Based on Table 4, the results of the quality of life analysis measured by patient satisfaction with the treatment of health workers at Dustira Cimahi Hospital found that most of the respondent who had taken both PCI and non-PCI measures were satisfied $(82,3 \%)$. Patient satisfaction with the doctor's explanation at Dustira Cimahi Hospital, it was found that most of the respondents who had performed PCI were very satisfied $(58.8 \%)$, and respondents with non-PCI measures who were satisfied were $82.3 \%$. Most of the respondents who had PCI action were very satisfied with the treatment at Dustira Cimahi Hospital (64.7\%), and respondents with non-PCI measures who were satisfied with the treatment at Dustira Cimahi Hospital as much as $100.0 \%$.

Table 5 shows the quality of life as measured by patients' perceptions of disease with reperfusion therapy, it was found that most of the respondents who had undergone PCI were rarely worried about the possibility of a heart attack $(47.0 \%)$, and respondents who had performed non-PCI were sometimes worried about the possibility of a heart attack. 58.8\%.

The quality of life of STEMI patients who have undergone both PCI and non-PCI measures was obtained from the results of calculating the scores of the five clinical dimensions on the SAQ. Table 6 shows the comparison of the results of measuring the quality of life of respondents who have taken PCI and Non-PCI measures at Dustira Cimahi Hospital, as follows:
TABLE VI. DISTRIBUTION OF MEAN QUALITY OF LIFE FOR STEMI PATIENTS BY REPERFUSION THERAPY

\begin{tabular}{|c|c|c|c|c|c|}
\hline Variable & n & Mean & SD & T (T-test) & P-value $*$ \\
\hline PCI & 17 & 66.06 & 6.95 & 5.86 & 0,000 \\
\hline Non-PCI & 17 & 52.18 & 6.85 & & \\
\hline
\end{tabular}

Table 6 above shows that out of 17 respondents who have undergone PCI have a mean score of quality of life is 66.06, while respondents who haven't undergo non-PCI get an average score of 52.18. The group that had PCI had a better SAQ score of 13.88 points compared to the group that had non - PCI.

These results indicated that the group that had been treated with PCI had a better quality of life than the group that had been treated with non - PCI. The results of statistical tests using the independent $\mathrm{T}$ test as in Table 6 above show that there is a very significant comparison between the quality of life of respondents who have undergone PCI and Non-PCI ( $\mathrm{p}=$ $0.000)$.

The results of this study are similar to studies conducted by Keeley et al., that reperfusion with PCI causes normal blood flow in the associated infarct arteries to reach $90-95 \%$, but only $50-60 \%$ in patients treated with fibrinolytic drugs $[42,43]$. The Boden et al., study also showed a degree of freedom from angina of about $66 \%$ in the PCI group and $58 \%$ in the medical therapy group (Non-PCI) [25].

These things may be explained by the atherosclerotic plaque breakdown mechanism which results in the opening of the blocked coronary arteries above $90 \%$ so that blood flow returns smoothly and the embolization and recurrent infarction is reduced. Blood flow that returns smoothly causes tissue reperfusion throughout the body to improve again $[19,26,43]$. Fibrinolytic drugs are successful in resolving thrombus, but they do not immediately resolve the ruptured plaque. The effectiveness of fibrinolytic drugs also decreases rapidly as the time from symptom onset exceeds two hours. Necropsy studies have shown that the onset of reperfusion injury and haemorrhagic transformation of myocardial infarction is common after fibrinolytic therapy [43].

\section{CONCLUSION AND SUGGESTION}

\section{A. Conclusion}

Based on the results of the comparative study of the quality of life of STEMI patients who were treated with PCI and NonPCI at Dustira Cimahi Hospital, the following conclusions can be drawn:

- An overview of the quality of life of STEMI patients who underwent PCI at Dustira Cimahi Hospital as measured using SAQ got an average score of 66.06.

- An overview of the quality of life of STEMI patients who underwent Non-PCI measures at Dustira Cimahi 
Hospital as measured using SAQ got an ever age score $52,=18$.

- Quality of life as measured by SAQ in STEMI patients after PCI was 13,88 points better than patients who had non-PCI treatment at Dustira Cimahi Hospital, and there was a very significant difference between the quality of life of patients undergoing PCI with non-PCI action at Dustira Cimahi Hospital.

\section{B. Suggestions}

Based on the research results, the suggestions that can be submitted are:

- It is expected that this study may be one of the sources for further research relating to the Quality of Life for STEMI patients who undergo PCI and non - PCI, which is seen from the terms of the activity of the physical, pain frequency, stability pain, patient satisfaction, and perceptions of the disease.

- It is hoped that future studies will examine the comparison between the quality of life of STEMI patients before and after PCI and the quality of life of STEMI patients before and after non - PCI

- It is expected that STEMI patients can choose reperfusion therapy with PCI because the patient's quality of life is better after PCI.

- It is hoped that satisfactory health services and health facilities at Dustira Cimahi Hospital will be maintained or improved.

\section{REFERENCES}

[1] World Health Organization, Global Atlas on Cardiovascular Disease Prevention and Control, WHO, 2011.

[2] World Health Organization, Cardiovascular Diseases (CVDs), 2017 [Online] Retrieved from: http://www.who.int/en/news-room/factsheets/detail/cardiovascular-diseases-(cvds)

[3] A.S. Simon, and T. Vijayakumar, "Molecular Studies on Coronary Artery Disease - A Review," Indian journal of clinical biochemistry, vol. 28, pp. 215-226, 2013.

[4] Kementerian Kesehatan RI, Info DATIN Pusat Data dan Informasi Kementerian Kesehatan RI: Situasi Kesehatan Jantung. Jakarta: Kemenkes RI, 2014

[5] Kementerian Kesehatan RI, Penyakit Jantung Penyebab Kematian Tertinggi, Kemenkes Ingatkan Cerdik. Jakarta: Kemenkes RI, 2017.

[6] Badan Penelitian dan Pengembangan Kesehatan Kementerian Kesehatan RI, Riset Kesehatan Dasar 2013. Jakarta: BPPK Kemenkes RI, 2013.

[7] Badan Penelitian dan Pengembangan Kesehatan Kementerian Kesehatan RI, Riskesdas Dalam Angka Provinsi Jawa Barat, Jakarta: BPPK Kemenkes RI, 2013.

[8] Perhimpunan Dokter Spesialis Kardiovaskular Indonesia, Panduan Praktik Klinis (PPK) dan Clinical Pathway (CP) Penyakit Jantung dan Pembuluh Darah, Perhimpunan Dokter Spesialis Kardiovaskular Indonesia, 2016.

[9] Washington State Department of Health, Coronary Heart Disease. Washington State Department of Health, 2013, p. 1-10.
[10] V. Kumar, A.K. Abbas, and J.C. Aster, Robbins Basic Pathology. 9th ed Canada: Elsevier, 2013, p. 329-34.

[11] Perhimpunan Dokter Spesialis Kardiovaskular Indonesia, Pedoman Tatalaksana Sindrom Koroner Akut. Perhimpunan Dokter Spesialis Kardiovaskular Indonesia, 2015.

[12] Global Data, Acute Coronary Syndrome (ACS) - Epidemiology Forecast to 2023. Global Data, 2014

[13] K.J. Overbaugh, "Acute Coronary Syndrome - Even Nurses Outside the ED Should Recognize Its Signs and Symptoms," AJN The American Journal of Nursing, vol. 109, pp. 42-52, 2009.

[14] L. Erhardt, J. Herlitz, L. Bossaert, M. Halinen, M. Keltai, R. Koster, and H. Van Weert, "Task force on the management of chest pain," European heart journal, vol. 23, pp. 1153-1176, 2002.

[15] N. Karam, S. Bataille, E. Marijon, M. Tafflet, F. Lapostolle, C. Spaulding, and e-MUST study investigators, "Is near-time prevention for sudden cardiac arrest feasible? The e-MUST score," Journal of thoracic disease, vol. 9, pp. E583, 2017.

[16] C. Arampatzis, E.P. McFadden, L.K. Michalis, R. Virmani, and P.W Serruys, Coronary Atherosclerosis - Current Management and Treatment. United Kingdom: Informa Healthcare, 2012.

[17] B.P. Griffin, Manual of Cardiovascular Medicine. 4th ed. Philadelphia: Lippincott Williams \& Wilkins, A Wolters Kluwer Business, 2013

[18] A. Hidayati, E. Erwin and A.P. Dewi, Persepsi Penyakit Jantung Koroner yang Akan Dilakukan Tindakan Kateterisasi Jantung. Riau: Riau University, 2015.

[19] S. Rifqi, "Primary Percutaneous Coronary Intervention (Primary PCI), Senjata "Baru" Untuk Melawan Serangan Jantung Akut," Medica Hospitalia, vol. 1, pp. 139-142, 2012.

[20] World Health Organization, Programme On Mental Health - WHOQOL (WHO Quality of Life) Measuring Quality of Life. World Health Organization, 1997.

[21] N.T. Yulianti, C.E. Kosasih, and E. Emaliyawati, Gambaran Kualitas Hidup Pasien Acute Coronary Syndrome di Poliklinik Jantung Rumah Sakit Al Islam Bandung, Bandung: Unpad, 2016.

[22] J.A. Spertus, J.A. Winder, T.A. Dewhurst, R.A. Deyo, J. Prodzinski, M McDonnell, and S.D. Fihn, "Development and evaluation of the Seattle Angina Questionnaire: a new functional status measure for coronary artery disease," Journal of the American College of Cardiology, vol. 25, pp. 333-341, 1995.

[23] W.S. Weintraub, J.A. Spertus, P. Kolm, D.J. Maron, Z. Zhang, C Jurkovitz, and W.E. Boden, "Effect of PCI on quality of life in patient with stable coronary disease," New England Journal of Medicine, vol. 359 , pp. 677-687, 2008

[24] F.J. Neumann, M. Sousa-Uva, A. Ahlsson, F. Alfonso, A.P. Banning, U. Benedetto, and M.O. Zembala, "2018 ESC/EACTS Guidelines on myocardial revascularization," European heart journal, vol. 40, pp. 87165,2019

[25] W.E. Boden, R.A. O'Rourke, K.K. Teo, P.M. Hartigan, D.J. Maron, W.J. Kostuk, and W.S. Weintraub, "Optimal medical therapy with or without PCI for stable coronary disease," New England journal of medicine, vol. 356, pp. 1503-1516, 2007.

[26] A.W. Sudoyo, B. Setiyohadi, I. Alwi, K.M. Simadibrata, and S. Setiati, Ilmu Penyakit Dalam. Jakarta: Interna Publishing, 2016.

[27] S.M. Alhassan, H.G. Ahmed, B.A. Almutlaq, A.A. Alanqari, R.K Alshammari, and K.T. Alshammari, "Risk Factors Associated with Acute Coronary Syndrome in Northern Saudi Arabia," Search of a Perfect Outfit. J Cardiol Curr Res, vol. 8, pp. 00281, 2017.

[28] L. Marleni, and A. Alhabib, "Faktor Risiko Penyakit Jantung Koroner di RSI SITI Khadijah Palembang," Jurnal Kesehatan, vol. 8, pp. 478-483, 2017.

[29] W. Yunyun, L. Tong, L. Yingwu, L. Bojiang, W. Yu, H. Xiaomin, and J. Li, "Analysis of risk factors of ST-segment elevation myocardia infarction in young patients," BMC cardiovascular disorders, vol. 14, pp. $1-6,2014$ 
[30] K.L. Moore, and A.F. Dalley, Clinically oriented anatomy. Wolters kluwer india Pvt Ltd, 2018.

[31] D.L. Kasper, S.L. Hauser, J.L. Jameson, A.S. Fauci, D.L. Longo, and J. Loscalzo, Harrison's Principles of Internal Medicine. 18th ed. United States: McGraw-Hill Education, 2015.

[32] Departemen Kesehatan RI, Pharmaceutical Care untuk Pasien Penyakit Jantung Koroner: Fokus Sindrom Koroner Akut. Jakarta: Departemen Kesehatan RI, 2006.

[33] F.M. Fesmire, W.J. Brady, S. Hahn, W.W. Decker, "Clinical Policy: Indications for Reperfusion Therapy in Emergency Department Patients with Suspected Acute Myocardial Infarction," American College of Emergency Physicians, vol. 48, pp. 358-383, 2006.

[34] E.R. Bates, Reperfusion Therapy for Acute Myocardial Infarction. New York: Informa Healthcare, 2008, p. 91-109.

[35] P.J. Scanlon, D.P. Faxon, A.M. Audet, B. Carabello, G.J. Dehmer, K.A. Eagle, and S.C. Smith Jr, "ACC/AHA Practice Guidelines-ACC/AHA Guidelines for Coronary Angiography: Executive Summary and Recommendations: A Report of the American College of Cardiology/American Heart Association Task Force," Circulation, vol. 99, pp. 2345, 1999.

[36] E. Braunval'd, E. Braunwald, and E. Braunwald, "The thrombolysis in myocardial infarction (TIMI) study group experience," Therapeutic archive, vol. 81, pp. 78-83, 2009.

[37] W.A. Tan and D.J. Moliterno, "TIMI Flow and Surrogate End Points: What You See is Not Always What You Get," vol. 136, pp. 570-573, 1998.
[38] S.H. Rampengan, Kardiologi UI. Jakarta: Fakultas Kedokteran Universitas Indonesia, 2014.

[39] S. Schroter, and D.L. Lamping, "Responsiveness of the Coronary Revascularisation Outcome Questionnaire Compared with the SF-36 and Seattle Angina Questionnaire," Quality of Life Research, vol. 15, pp. 1069-1078, 2006.

[40] L.P. Kimble, S.B. Dunbar, W.S. Weintraub, D.B. McGuire, S. Fazio, A.K. De, and O. Strickland, "The Seattle angina questionnaire: reliability and validity in women with chronic stable angina," Heart disease (Hagerstown, Md.), vol. 4, pp. 206, 2002.

[41] W. Jie, H.E. Qing-yong, and Z. Yun-ling, "Effect of Shenshao Tablet (参莐片) on the Quality of Life for Coronary Heart Disease Patients with Stable Angina Pectoris," Chin J Integr Med, vol. 15, pp. 328-332, 2009.

[42] E.C. Keeley, J.A. Boura, and C.L. Grines, "Primary Angioplasty versus Intravenous Thrombolytic Therapy for Acute Myocardial Infarction: A Quantitative Review of 23 Randomised Trials," Lancet, vol. 361, pp. 13-20, 2003.

[43] E.V. Gelfand and C.P. Cannon, Management of Acute Coronary Syndromes. UK: John Wiley \& Sons Ltd, 2009.

[44] D.J. Cohen, B. Van Hout, P.W. Serruys, F.W. Mohr,C. Macaya, P. Den Heijer, and A.P. Kappetein, "Quality of life after PCI with drug-eluting stents or coronary-artery bypass surgery," New England Journal of Medicine, vol. 364, pp. 1016-1026, 2011. 